\title{
OBSTETRIC OUTCOME IN WOMEN WITH PRELABOUR RUPTURE OF MEMBRANES AT TERM PREGNANCY
}

\author{
Jonna Malathi ${ }^{1}$, Venigalla Sunita² \\ ${ }_{1}^{1}$ Assistant Professor, Department of Obstetrics and Gynaecology, SVIMS, Sri Padmavathi Medical College for Women, Tirupati. \\ ${ }^{2}$ Professor, Department of Obstetrics and Gynaecology, Sri Devaraj Urs Medical College, Tamaka, Kolar, Karnataka.
}

ABSTRACT: OBJECTIVES: To study the maternal outcome associated with prelabour rupture of membranes at term. To assess the fetal outcome associated with prelabour rupture of membranes at term.

MATERIALS AND METHODS: This is a prospective study conducted in the Department of Obstetrics and Gynaecology, at R.L. Jalappa Hospital and Research Centre attached to Sri Devraj Urs Medical College from December 2010 to September 2012, where patients confirmed with PROM at term were recruited and monitored for progress of labour as well as mode of delivery. Maternal and neonatal outcome was noted.

RESULTS: 263 cases of PROM were studied during the study period, which met the inclusion and exclusion criteria. The incidence of PROM in this hospital is 7.06\%. Majority of the patients belonged to the age group of 21-25 years (64.2\%), with primigravida being $59.3 \%$. Risk factor for PROM was unknown in $84.5 \%$ of cases with $7.6 \%$ giving history of PROM in previous pregnancy. The other risk factors in our study were breech (3.8\%), history of recent coitus (1.9\%), and polyhydramnios (1.2\%); $94.7 \%$ delivered vaginally and 5.3\% underwent cesarean section. Among vaginal delivery $2.3 \%$ were assisted breech deliveries, $1.5 \%$ outlet forceps delivery and 37.3 were induced to deliver. Indications for cesarean section were CPD (42.8\%), breech (28.6\%), failure to progress (14.3\%), and failed induction (14.3\%). Two patients had chorioamnionitis and 11 babies were admitted in NICU for respiratory distress (2 babies), birth asphyxia ( 6 babies), and early onset of sepsis ( 3 babies).

CONCLUSION: In the absence of any maternal and/or obstetric risk factors, PROM does not seem to constitute additional obstetric risks.

KEYWORDS: Prelabour rupture of membrane, Chorioamnionitis, Respiratory Distress, Birth Asphyxia, Maternal Morbidity, Perinatal Morbidity.

HOW TO CITE THIS ARTICLE: Jonna Malathi, Venigalla Sunita. "Obstetric Outcome in Women with Prelabour Rupture of Membranes at Term Pregnancy." Journal of Evolution of Medical and Dental Sciences 2015; Vol. 4, Issue 94, November 23;

Page: $15960-15962$, DOI: $10.14260 /$ jemds/2015/2325.

INTRODUCTION: Prelabour rupture of membranes (PROM) is defined as rupture of the membranes prior to the onset of labour at or beyond 37 weeks' gestation. ${ }^{1}$ PROM without development of active labour occurs in $8 \%$ of term pregnancies. ${ }^{2}$ It is a significant event as it leads to increased maternal complications, operative procedures, neonatal morbidity and mortality. The management of a case of prelabour rupture of membranes has remained as one of the most difficult and controversial problems in obstetrics over the past several decades.

The mechanism of PROM is unknown. No standards for diagnosis exist and most facts of management are controversial. PROM is a major cause for prematurity, which leads to increased perinatal morbidity and mortality. At least $60 \%$ of cases of prelabour rupture of membranes occur at term. Spontaneous labour follows term PROM at 24, 48, 96 hours in $70 \%, 85 \%$ and $95 \%$ of women respectively. Studies in the period 1960-80 showed an increased risk of maternal and perinatal morbidity and mortality when the time interval from rupture of the membranes until delivery was prolonged.

Financial or Other, Competing Interest: None.

Submission 02-11-2015, Peer Review 03-11-2015,

Acceptance 13-11-2015, Published 21-11-2015.

Corresponding Author:

Dr. Jonna Malathi,

$777 / P, H A L, 2^{\text {nd }}$ Stage,

$13^{\text {th }}$ Main, $1^{\text {st }}$ Cross,

Indiranagar-560008, Bangalore

Karnataka, India.

E-mail: malathi_jonna@yahoo.co.in

DOI:10.14260/jemds/2015/2325.
This fact was the main reason why a policy of immediate induction of labour after PROM at term was adopted. ${ }^{3}$

The incidence of chorioamnionitis in women at term with prelabour rupture of the membranes is $6-10 \%$ and occurs in up to $40 \%$ of women with membrane rupture $>24$ hours. Increasing numbers of digital vaginal examinations, longer duration of active labour and meconium staining of the amniotic fluid are the most important risk factors for the development of chorioamnionitis. With increasing time elapsed since prelabour rupture of membranes to delivery, significant increase in incidences of induced labour, operative delivery, fetal distress, poorer fetal condition at birth, neonatal infections and maternal infection are noticed.

Some authors believe that expectant management of prelabour rupture of membranes at term does not increase perinatal and maternal morbidity and an aggressive attitude to prelabour rupture of membranes with immediate induction of labour leads to increased caesarean section. ${ }^{4}$ The best maternal and neonatal outcomes are obtained if delivery occurs within 12 hours after premature rupture of membranes. ${ }^{5}$ Administration of antibiotics was associated with reduction of maternal and neonatal morbidity and mortality. ${ }^{6}$

\section{OBJECTIVES:}

- To study the maternal outcome associated with prelabour rupture of membranes at term.

- To assess the fetal outcome associated with prelabour rupture of membranes at term.

MATERIALS AND METHODS: The study was conducted at the Department of Obstetrics and Gynaecology, R.L Jalappa Hospital and Research Centre attached to Sri Devaraj Urs Academy of Higher Education and Research, Tamaka, Kolar, 
between December 2010 to September 2012. All the women who came with complaint of prelabour rupture of membranes that met the inclusion and exclusion criteria were studied.

\section{Inclusion Criteria:}

Patients with leaking of liquor and having:

1. Gestational age $>37$ weeks,

2. Primigravida/Multigravida,

3. Singleton pregnancy.

\section{Exclusion Criteria:}

1. Contraindication to induction of labour,

2. Previous cesarean section,

3. Cases of antepartum haemorrhage,

4. Congenital anomalies/Intrauterine death,

5. Medical conditions like heart disease/uncontrolled diabetes mellitus/severe pre-eclampsia,

6. Meconium stained amniotic fluid/Fetal distress.

The study was approved by the ethical committee. Patients with history of prelabour rupture of membranes before onset of labour pain were admitted to labour room. A detailed history was taken including age, menstrual and obstetric history with emphasis on exact time of rupture of membranes, duration and amount of leak. In general examination - Pulse, BP, temperature was noted followed by systemic examination. In obstetric examination - Uterine height, presentation, position, lie of fetus and amount of liquor were noted. All parameters of maternal and fetal well-being were recorded. A detailed history was taken regarding relevant medical and surgical information.

A sterile speculum examination was conducted and presence of liquor amnii was noted. When no amniotic fluid was seen in the vagina, patient was asked to cough to see drainage of amniotic fluid. A vaginal examination was performed to rule out cephalopelvic disproportion and to assess Bishop's score. Gestational age was evaluated by last menstrual period and ultrasound. Ultrasound was done for assessing gestational age, liquor volume, fetal well-being. Fetal condition was assessed by NST tracing. Samples were collected for baseline laboratory tests.

For diagnosis of chorioamnionitis, clinical criteria (i.e. Maternal pulse and temperature, fetal tachycardia, uterine irritability and tenderness) were used. All study cases were given prophylactic antibiotic. Occurrence of fever, gastrointestinal symptoms, hyperstimulation and postpartum haemorrhage were evaluated.

Fetal criteria including presence of thick meconium in the amniotic fluid, fetal distress as defined by abnormal CTG promoting emergency delivery, APGAR scores at one minute and five minutes, transfer to NICU were evaluated.

RESULTS: 312 patients came with prelabour rupture of membranes at term, during the study period from December 2010 to September 2012, of which 263 cases met the inclusion and exclusion criteria; 49 cases were excluded from the study as they did not meet the inclusion and exclusion criteria.

\begin{tabular}{|c|c|c|}
\hline $\begin{array}{c}\text { AGE GROUP (In } \\
\text { years) }\end{array}$ & $\begin{array}{c}\text { STUDY GROUP } \\
\text { (n=263) }\end{array}$ & PERCENTAGE \\
\hline$\leq 20$ & 19 & 7.2 \\
\hline $21-25$ & 169 & 64.2 \\
\hline $26-30$ & 68 & 25.9 \\
\hline $31-35$ & 7 & 2.7 \\
\hline \multicolumn{2}{|c|}{ Table 1: Age Distribution in Prom Patients } \\
\hline
\end{tabular}

This table shows age distribution of patients with PROM Majority of the patients belong to age group 21-25 years. Mean age of the patients was 23.6 years.

\begin{tabular}{|c|c|c|}
\hline GRAVIDITY & $\begin{array}{c}\text { STUDY GROUP } \\
(\mathbf{n = 2 6 3 )}\end{array}$ & PERCENTAGE \\
\hline Primigravida & 156 & 59.3 \\
\hline G2 & 78 & 29.7 \\
\hline G3 & 24 & 9.1 \\
\hline G4 & 2 & 0.7 \\
\hline G5 & 3 & 1.2 \\
\hline Table 2: Gravidity Distribution in Prom Patients \\
\hline
\end{tabular}

This table shows that PROM occurs more frequently in primigravida compared to that of multigravida patients.

\begin{tabular}{|c|c|c|}
\hline $\begin{array}{c}\text { GESTATIONAL AGE } \\
\text { (In weeks) }\end{array}$ & $\begin{array}{c}\text { STUDY GROUP } \\
(\mathbf{n = 2 6 3})\end{array}$ & PERCENTAGE \\
\hline $37-40$ & 212 & 80.6 \\
\hline $40-42$ & 51 & 19.4 \\
\hline \multicolumn{2}{|c|}{ Table 3: Gestational Age Distribution in Prom Patients } \\
\hline
\end{tabular}

$80.6 \%$ of patients were between $37-40$ weeks of gestation. Only $19.4 \%$ had crossed 40 weeks of gestation, where most of them were unbooked cases.

\begin{tabular}{|c|c|c|}
\hline $\begin{array}{c}\text { ANTENATAL } \\
\text { CARE }\end{array}$ & $\begin{array}{c}\text { STUDY GROUP } \\
(\mathbf{n = 2 6 3 )}\end{array}$ & PERCENTAGE \\
\hline Booked & 219 & 83.3 \\
\hline Unbooked & 44 & 16.7 \\
\hline \multicolumn{2}{|c|}{ Table 4: Antenatal Care in Prom Patients } \\
\hline
\end{tabular}

This table shows that there is no correlation between antenatal care and PROM.

\begin{tabular}{|c|c|c|}
\hline RISK FACTORS & $\begin{array}{c}\text { STUDY GROUP } \\
(n=263)\end{array}$ & PERCENTAGE \\
\hline Unknown & 225 & 85.5 \\
\hline $\begin{array}{c}\text { Previous history of } \\
\text { PROM }\end{array}$ & 20 & 7.6 \\
\hline Breech & 10 & 3.8 \\
\hline $\begin{array}{c}\text { History of recent } \\
\text { coitus }\end{array}$ & 5 & 1.9 \\
\hline Polyhydramnios & 3 & 1.2 \\
\hline
\end{tabular}

This table shows the risk factors in relation to PROM. Majority of the cases the risk factor is unknown (85.5\%) and history of previous PROM (7.6\%) is the next major risk factor.

\begin{tabular}{|c|c|c|}
\hline $\begin{array}{c}\text { MODE OF } \\
\text { DELIVERY }\end{array}$ & $\begin{array}{c}\text { STUDY } \\
\text { GROUP } \\
\text { (n=263) }\end{array}$ & PERCENTAGE \\
\hline $\begin{array}{c}\text { Full term vaginal delivery with } \\
\text { oxytocin }\end{array}$ & 141 & 53.6 \\
induction/augumentation & 6 & 2.3 \\
\hline Assisted breech delivery & 4 & 1.5 \\
\hline Outlet forceps delivery & 98 & 37.3 \\
\hline $\begin{array}{c}\text { Vaginal delivery with } \\
\text { prostaglandin induction }\end{array}$ & 14 & 5.3 \\
\hline \multicolumn{2}{|c|}{ LSCS } & Table 6: Mode of Delivery in Prom Patients \\
\hline \multicolumn{2}{|c|}{}
\end{tabular}


Majority of the patients with good Bishop's score were augmented with oxytocin and delivered vaginally (53.6\%).

\begin{tabular}{|c|c|c|}
\hline INDICATIONS & $\begin{array}{c}\text { STUDY } \\
\text { GROUP } \\
\text { (n=14) }\end{array}$ & PERCENTAGE \\
\hline Breech & 4 & 28.6 \\
\hline Undiagnosed CPD & 3 & 21.4 \\
\hline DTA & 3 & 21.4 \\
\hline $\begin{array}{c}\text { Failure to progress } \\
\text { with oxytocin }\end{array}$ & 2 & 14.3 \\
\hline $\begin{array}{c}\text { Failed induction with } \\
\text { prostaglandin }\end{array}$ & 1 & 7.15 \\
\hline $\begin{array}{c}\text { Fetal distress with } \\
\text { prostaglandin }\end{array}$ & 1 & 7.15 \\
\hline \multicolumn{2}{|c|}{ Table 7: Indications for LSCS in Prom Patients } \\
\hline
\end{tabular}

Breech $(28.6 \%)$ was the most common indication for LSCS.

\begin{tabular}{|c|c|c|}
\hline COMPLICATIONS & $\begin{array}{c}\text { STUDY } \\
\text { GROUP }\end{array}$ & PERCENTAGE \\
\hline Chorioamnionitis & 2 & 0.8 \\
\hline Puerperal pyrexia & 2 & 0.8 \\
\hline Wound infection & 1 & 0.4 \\
\hline $\begin{array}{c}\text { Foul smelling } \\
\text { lochia }\end{array}$ & 2 & 0.8 \\
\hline \multicolumn{2}{|c|}{ Table 8: Maternal Morbidity in Prom Patients } \\
\hline
\end{tabular}

Two patients in the induced group had all the above complications. One patient was delivered by cesarean section, who had wound infection postoperatively.

\begin{tabular}{|c|c|c|}
\hline COMPLICATIONS & STUDY GROUP & PRECENTAGE \\
\hline Respiratory distress & 2 & 0.8 \\
\hline Early onset sepsis & 3 & 1.2 \\
\hline Birth asphyxia & 6 & 2.4 \\
\hline \multicolumn{2}{|c|}{ Table 9: Noenatal Morbidity in Prom Patients } \\
\hline
\end{tabular}

Eleven babies were admitted in NICU; $2.4 \%$ was due to birth asphyxia.

DISCUSSION: Prelabour rupture of the membrane is one of the common and challenging problems in perinatal medicine today. PROM is a fairly common complication in term pregnancy and can lead to increased maternal morbidity, operative procedures, neonatal morbidity and mortality. The incidence of PROM in our hospital is 7.06\%.

PROM before onset of uterine contraction is commonly associated with obstetric risk factors such as unstable lie, multiple pregnancy, and polyhydramnios. However, in the majority of cases of PROM, there is no obvious cause(s). In the absence of such evidence or other obstetric indications for immediate delivery, the most appropriate choice of management of PROM is still controversial. Immediate induction of labour in case of PROM is a standard practice to avoid potential complications of intrauterine infection and oligohydramnios.

The lower age in this study is probably due to early age at marriage and pregnancy in the region. The mean age of 23.6 years in the present study is similar to the study done by Didem Akyol and Collegues. ${ }^{7}$ In the present study, $80.6 \%$ of women belong to gestational age between $37-40$ weeks with average gestational age being 39.1 weeks and $19.4 \%$ belonged to gestational age between 40-42 weeks. Gestational age in our study is similar to all the other studies. ${ }^{8,9}$ In our study, $59.3 \%$ were primigravida, which is comparable with study done by Yossef Ezra and Colleagues. ${ }^{10}$

A $5.3 \%$ of cases delivered by caesarean section in our study and its comparable to study done by Tarik $\mathrm{Y}$ and Colleagues. ${ }^{11}$ There were 2 cases of chorioamnionitis and 2 cases of postpartum haemorrhage in our study and it is less compared to other studies.8,10 NICU admissions in our study are comparable to Ben Chong et al. study. ${ }^{9}$

CONCLUSION: The results of the present study suggest that in the absence of any maternal and/or fetal risk factors, PROM per se does not constitute an additional obstetric risk. Deliveries occurring more than $12 \mathrm{hrs}$ after PROM put the mother at risk of having an operative delivery and minor infections, and put the baby at risk of fetal distress, sepsis. Active management of term PROM with induction is associated with reduced maternal infective morbidity without increasing caesarean section or operative vaginal birth.

\section{REFERENCES:}

1. Stephen R, Susan W, Gino P, Yee L, Anuschirawan Y, Simon C et al. Term Prelabour Rupture of Membranes. RANZCOG 2010; 36:1-3.

2. Yossef E, Rachel MC, Yoram A, Nathan R. Prelabour rupture of membranes at term: When to induce? European Journal of Obstetrics \& Gynaecology and Reproductive Biology 115 (2004) 23-27.

3. Ladfors L, Mattsson LA, Eriksson M, Fall O. A randomised trial of two expectant managements of prelabour rupture of the membranes at 34 to 42 weeks. Br J Obstet Gynaecol 1996; 103:755-762.

4. Chaudhuri S, Nath MS, Biswas PK, Bhattacharyya S. PROM at term: Immediate induction with $\mathrm{PGE}_{2}$ gel compared with delayed induction with oxytocin. J Obstet Gynecol India 2006; 56(3); 224-229.

5. Marowitz A. Midwifery management of prelabour rupture of membranes at term. J Midwifery Womens Health 2007; 52(3); 199-206.

6. Kenyon S, Boulvain M, Neilson J. Antibiotics for premature rupture of membranes: A Systemic review. Obstet and Gynecol 2004:104(5):1051-7.

7. Didem A, Tamer M, Aydin U, Kutlugul Y, Zekai TB. Prelabour Rupture of the Membranes at Term - No Advantage of Delaying Induction for 24 Hours. Aust NZ J Obstet Gynecol 1999; 39(3):291-295.

8. Farhat K, Mamoona M. Term prelabour rupture of membranes: Management and outcome. PAFMJ 2006; 3:1-2.

9. Ben CPC, Terence TH, Lao W, Cheong L. Prelabor rupture of membranes at term requiring labor induction - A feature of occult fetal cephalopelvic disproportion? Perinat. Med. 2009; 37: 118-123.

10. Tarik Y, Yamani, Hassan A, Nasrat, Bahaa A, Abalkhail. Management of Rupture of Membranes at term in LowRisk Obstetric Population. J KAU Med. Sci.1997; 7 (1):49. 55.

11. Nili F, Shams AA. Neonatal Complications of Premature Rupture of Membranes. Acta Medica Iranica 2003; 41:175-179. 